\title{
LXXXVIII. On the theory of vanishing fractions
}

\section{J.R. Young Esq.}

To cite this article: J.R. Young Esq. (1836) LXXXVIII. On the theory of vanishing fractions, Philosophical Magazine Series 3, 8:49, 515-521, DOI: 10.1080/14786443608648930

To link to this article: http://dx.doi.org/10.1080/14786443608648930

册 Published online: 01 Jun 2009.

Submit your article to this journal 준

Џ Article views: 3

Q View related articles $₫$ 
Euphrates between these two points and the breadth of its bed in the lower portion of its course, both which causes must produce a corresponding diminution in its speed, and on the other hand the contraction of the channel of the Tigris, which must be attended with a corresponding acceleration of the motion of its waters.

Col. Chesney is referred to as describing the Euphrates as in the present day flowing in a dull and lingering stream: Herodotus, also an eye-roitness, in his description of Babylon talks of the "deep and rapid streams of the great Euphrates*." No one will for a moment doubt the accuracy of Col. Chesney's observation; but is not credit also due to Herodotus? and is he, in like manner as Arrian, to be " unceremonionsly thrown overboard," whilst the facts respecting the former condition of these rivers remain unascertained? In the passage last cited, the Halicarnassian traveller further expressly asserts that the Euphrates "discharges itself into the Persian Gulf;" which assertion he confirms in his more detailed statement that that river, " which before flowed in an almost straight line," had its course so turned by Nitocris, that in his time, "those who wished to go from the sea up to Babylon were compelled to touch at Ardericca three times on three different days.$+ "$ Surely such unqualified and unequivocal assertions of plain matters of fact are entitled to consideration, and are not to be put aside as errors simply because they are not applicable to the present state of things, or rather, perhaps, because they do not coincide with what we have been taught by former commentators to receive as the truth.

[To be continued.]

LXXXVIII. On the Theory of Vanishing Fractions. By J. R. Young, Esq., Professor of Mathematics in Belfast College. $\neq$

W a letter inserted in the April number of this Journal (p. 295) I ventured to offer some objections to certain novel positions, lately advanced by an ingenious mathematician, in an Essay on the Fundamental Principles of the Differential and Integral Calculus. To these objections the author of the Essay has furnished a reply, in the number for May (p. 393); and I am happy to find, from the general tone of it, that Mr. Woolhouse has considered my scruples with the same good feeling in which they were avowedly offered.

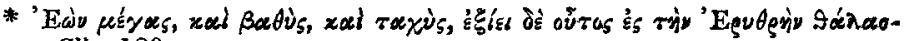
$\sigma x y .-$ Clio, 180.

+ Clio, 185.

\pm Communicated by the Author. 


\section{Prof. Young on the Theory of Vanishing Fractions.}

In my former communication, I contented myself with simply pointing out the fallacy involved in the extremely general statements which I extracted from the Essay referred to; and with tracing the source of this fallacy to the circumstance of the author having unguardedly assumed the converse of a certain proposition, to be equally general with the proposition itself, which converse holds however only in particular cases.

The direct proposition to which I here allude is this, viz. that when in certain hypotheses any of the analytical conditions of a problem disappear, the final result, to which the general process leads, takes the form $\frac{0}{0}$. The converse proposition is, that when the final result takes the form $\frac{0}{0}$ original conditions must have disappeared. This latter is the affirmation distinctly conveyed, without the slightest qualification, in the propositions marked II. and III. in Mr. Woolhouse's reply; and it will be remembered, that against those propositions only my objections were directed; for I cheerfully admitted that much of Mr. Woolhouse's Essay was " in strict accordance with the usual notions of this doctrine."

To show that these objections were valid, I adduced an instance (that of a geometrical series) in which the propositions objected to would lead to error; and in adverting to this instance, in his reply, it will be seen that my respected friend has not defended the positions in question from the charge of making the sum of the said geometrical series anything, but has shown that another position (Prop. IV.), a position which was never impugned, is competent to supply the correct result. Surely my ingenious friend does not consider it to be a sufficient defence of Proposition III. to prove that its affirmations are neutralized by Proposition IV.; and yet there is no other attempt made to establish its truth. The proposition which Mr. Woolhouse discusses at page 395 , does not at all contribute to this object; for that is the converse of the one which it behoves him to prove, in order to establish his third principle: this principle requires the proposition stated above, in Italics, and not the one which Mr. Woolhouse has demonstrated in the preceding Number. There is no dispute as to the form of the result when conditions vanish; the question is, does this form necessarily imply vanishing conditions in the original analytical statement of the problem? Mr. Woolhouse's third principle unequivocally states it does. But innumerable examples to the contrary may be adduced. The well-known problem of Clairaut, which has for its object the determination of the spot between two lights, which is equally illuminated by both, is a case in point, and furnishes a satisfactory refutation of the 
principle in question, as may be seen by a reference to the Algebra of Lacroix, where the circumstances of the problem are discussed at length. The ordinary expression for the radius of curvature of a plane curve, will also furnish other examples of the fallacy of the assumed principle; for when, in any particular example, that expression takes the form of a fraction, as $r=\frac{\mathbf{P}}{\mathbf{Q}}$, we have, by differentiating,

$$
d r=\frac{\mathbf{Q} d \mathbf{P}-\mathbf{P} d \mathbf{Q}}{\mathbf{Q}^{2}} \ldots . . . . .
$$

and it is well known that whatever values of $x$ and $y$ render this expression equal to zero, the same values, provided they fulfill the original condition, or equation of the curve, will belong to points in it of maximum or minimum curvature; or to points at which the contact with the osculating circle is above the second order. Now it is plain that the conditions

$$
P=0, Q=0
$$

will cause a value of (1) to be zero; if, therefore, these conditions furnish for $x$ and $y$ values which satisfy the equation of the curve, the points to which they refer will be distinguished from the other points by the order of contact being higher there than elsewhere. Instead of deducing this conclusion from the expression $r=\frac{0}{\mathrm{o}}$, we ought, in accordance with Mr. Woolhouse's third principle, to say that at every such point the radii of curvature are innumerable, which is obviously absurd. As an example, let us take the common parabola, of which the equation is $y^{2}=4 m x$. By the usual process we obtain for $r$ the expression

$$
r=\left\{\frac{m+x}{x}\right\}^{\frac{3}{2}} \cdot \frac{y^{3}}{4 m^{2}}=\frac{\mathbf{P}}{\mathbf{Q}}
$$

and the conditions (2) are, in this case,

$$
(m+x)^{\frac{1}{2}} y=0,4 m^{2} x^{\frac{3}{2}}=0,
$$

which are satisfied by the values $x=0, y=0$; and these values, fulfilling the original condition $y^{3}=4 m x$, it follows that the origin of the axes, that is the vertex of the parabola, is a point at which the contact is above the second order, and this we know to be the case from other considerations.

It is unnecessary to multiply examples illustrative of the fallacy of this third principle "as a general rule," and indeed a passage in the reply of my talented friend leads me to suspect that, while writing that reply, he himself had some mis- 


\section{Prof. Young on the Throry of Vanishing Fractions.}

givings about it. The passage I refer to is at page 396, where Mr. Woolhouse, in his reasonings on the form $\frac{0}{0}$, limits his arguments to those comparatively few cases in which the results of that form are obtained in such a way, "that no multiplication or division by a power of $x-a$ occurs in the process." If only results obtained under such restrictions as these are admitted to come under the second and third principles, then the generality of those principles is of course at once given up, and my friend and I are thus far agreed. But then so limited a principle of interpretation falls greatly short of a general theory; and moreover requires, in its application, an acquaintance with the texture of the entire process too minute to be generally attainable; it requires, in fact, that we know the composition of every nultiplier and divisor employed, 一an impossible problem beyond certain limits.

At page 399, Mr. Woolhouse enters into a digression upon "the general theory of analytical results," respecting which he considers me to be in error, because in my last letter I had said that the fact of the ellipse question, admitting multiple solutions, was information which the analytical result was quite incompetent to supply; and he observes, "I never before heard of the incompetency of an analytical result to afford any positive information that an investigation could admit of." In this gratuitous admission of paucity of information upon subjects in which he so eminently excels, my friend has done himself a wanton injustice. He is too profoundly acquainted with all the subtleties of the Integral Calculus, and its applications, not to have "heard of" singular solutions, which, though not comprised in the resulting integrals which furnish the general solutions to certain differential equations, have, nevertheless, the property of satisfying the proposed conditions. But a more comprehensive view of the results of even common algebra, would, I think, have induced my friend to withhold the remark just quoted. Mr. Woolhouse ascertains the number of admissible solutions from "the nature of the problem." By taking a more enlarged view, it would have occurred to him that the result might furnish solutions, not only contrary to the express stipulations of the problem, but at variance with even the original analytical conditions, although these may have a much wider range. The results after these "solutions étrangères" are rejected from them, are those from among which are to be selected the solutions to the problem. In the present discussion it is the connexion between the analytical conditions and the analytical results, which is the matter before us; and it is, I suspect, from not keeping this in mind, that Mr. Woolhouse has been led to say, in mistake, 
that "Professor Young involves himself in a palpable inconsistency when he arrives at the fact of the ellipse question admitting multiple solutions, by an examination of the original analytical conditions, and at the same time alleges that the analytical result is quite incompetent to supply that information." The mathematical readers of this Journal will however readily perceive, that what is here charged as "palpable inconsistency" is in perfect accordance with the strictest analytical accuracy ; and that the "inconsistency" would have been, in inferring the multiple solutions from the analytical result, without reference to the original conditions, as Mr. Woolhouse has done, thus assuming (what is not true) that the converse of a certain proposition holds merely because the proposition itself is known to be true. Mr. Horner in the present volume of this Journal (p. 43.) has brought forward whole cluster of instances, in each of which, as he clearly shows, " the analytical result is quite incompetent to supply the information" even as to whether the question admits of a single solution, much less as to whether it admits of multiple solutions: the information sought must be obtained in all these cases, as I have obtained it in the ellipse question, viz. by a direct appeal to " the original analytical conditions." Without such an appeal how are we to know whether the analytical result to which the condition

leads, viz.

$$
2 x+\sqrt{x^{2}-7}=5
$$

$$
3 x^{2}-20 x+32=0,
$$

will supply values competent to satisfy that condition? The presumption is that it roill supply such values; upon trial however we find them to fail : and yet these values will satisfy the immediately antecedent equation, but this is not sufficient; every anterior step must be satisfied, up to the original equation inclusively; and the error committed in overlooking this would be precisely similar to that which Mr. Woolhouse appears to me to have committed, in inferring the multiple solutions to the ellipse question, merely because these solutions satisfy the final result *. The same mistaken view of the "theory of

* It is but justice to $\mathrm{Mr}$. Woolhouse to state, however, that he admits (p. 399) that " the nature of the problem, as originally presented, is the proper source of rejective information," although he maintains that the original analytical conditions do not furnish the proper source of information, as to whether, in certain hypotheses, one of those conditions becomes destroyed, or two or more of them become dependent; but, on the contrary, that the result $\frac{o}{o}$ is a sufficient indication that one or other of these circumstances must take place. (See III. p. 394.) I have endeavoured to show, however, that this result is not competent to furnish any information on the subject. 


\section{Prof. Young on the Theory of Vanishing Fractions.}

analytical results" accompanies his animadversions at page 398-9 in the last number of this Journal; he appears to think it sufficient that the antecedent equation should be satisfied, for he remarks, "The corresponding antecedent equation to the result $x=\frac{0}{0}$, when cleared of fractions, is $o x=0$, or $0=0$, an equation that is obviously satisfied without any limitation to the value of $x$, and that cannot fail therefore to be compatible with the other equations or conditions." The statement, in connexion with this remark, viz. that " $\frac{\mathrm{O}}{\mathrm{o}}$ can never be the symbol of absurdity," has a little surprised me, because the contrary is a fact so generally known to analysts. To occupy these pages by examples of this would be quite superfluous, as they abound in most of the Continental books on algebra. In the comprehensive work of Bourdon there is an ample supply of such examples, and from which he deduces the ordinary conclusion, viz. that "s le symbol $\stackrel{0}{\circ}$ est tantôt un caractère d'indétermination, tantôt un caractère d'absurdité."

From what has now been said of the symbol $\frac{0}{0}$, it appears that, when it is not the indication of absurdity, or of incompatible conditions, it may arise from either of these two causes: viz. from taking the ultimate, or limiting, value of $\frac{P}{Q}$, the general result of an analytical process ; or, without regard to this extreme limit, it may arise from the destruction of one or more of the conditional equations. One or other of these circumstances must take place in connexion with the occurrence of $\frac{0}{0}$, whenever this symbol is at all interpretable. I say whenever the symbol is interpretable, for cases may arise in which this symbol is indicative of neither multiple solutions, nor of limiting values, nor of incompatible conditions. In such cases therefore other modes of solution must be sought. The instances to which $I$ now allude are among those in which the vanishing of the numerator is not necessarily accompanied by the vanishing of the denominator; but where each vanishes independently, in virtue of distinct hypotheses introduced among the arbitrary quantities in each. With the exception of these unintelligible results, the occurrence of $\frac{o}{o}$ is always traceable to one or other of the circumstances before mentioned; which circumstances, although having no necessary connexion, may nevertheless, as in the case of the ellipse question, both exist simultaneously.

When therefore $\frac{o}{o}$ takes the place of $\frac{P}{Q}$, in any hypothesis, we may be assured that the limiting values of $\frac{P}{Q}$ will always 
subsist with the original analytical conditions, however they may be modified under the proposed hypothesis; but we can neither deny, nor affirm, that other values may also subsist with these conditions; for " this is information which the analytical result is quite incompetent to supply," and which must be derived solely from ascertaining the effect of the proposed hypothesis upon the original analytical restrictions; and that this is a fair and legitimate deduction from the foregoing examination, I think no person who enters into it with unbiassed judgement, will be disposed to deny.

Belfast, May 7 th, 1836.

LXXXIX. On the History of the Condensation of the Gases, in reply to Dr. Davy, introduced by some Remarks on that of Electro-magnetic Rotation. By Michael Faraday, Esq., D.C.L. F.R.S., \&c., in a Letter to Richard Phillips, Esq., F.R.S. L.\& E., \&c.

My dear Sir, Royal Institution, May 10, 1836.

I HAVE just concluded Jooking over Dr. Davy's Life of his brother Sir Humphry Davy. In it, between pages 160 and 164 of the second volume, the author links together some account, with observations, of the discovery of electro-magnetic rotation, and that of the condensation of the gases, concluding at page 164 with these words: "I am surprised that Mr. Faraday has not come forward to do him [Sir Humphry Davy] justice. As I view the matter, it appears hardly less necessary to his own honest fame than his acknowledgement to Dr. Wollaston, on the subject of the first idea of the rotary magnetic motion."

I regret that Dr. Davy by saying this has made that necessary which I did not before think so; but I feel that I cannot after his observation indulge my earnest desire to be silent on the matter without incurring the risk of being charged with something opposed to an honest character. This I dare not risk ; but in answering for myself, I trust it will be understood that I have been driven unwillingly into utterance.

Dr. Davy speaks of electro-magnetic rotation, and so also must $I$, for the purpose of showing certain coincidences in dates, \&c. between the latter part of that affair and the condensation of chlorine and the gases, \&c. Oersted's experiments were publised in 'Thomson's Annals of Philosophy for October 1820, and from this, I believe, was derived the first knowledge of them which we had in this country. At all events it was the first intimation Sir Humphry Davy and I had of them, for he brought down the Number into the laboratory on the morning of its appearance (October 1st) and we re- 